\title{
2D:4D Ratios in the First 2 Years of Life: Stability and Relation to Testosterone Exposure and Sensitivity
}

\author{
Rebecca C. Knickmeyer ${ }^{\mathrm{a}}$, Sandra Woolson ${ }^{\mathrm{a}}$, Robert M. Hamer ${ }^{\mathrm{a}, \mathrm{b}}$, Thomas Konneker ${ }^{\mathrm{c}}$, and \\ John H. Gilmore ${ }^{\mathrm{a}}$ \\ aDepartment of Psychiatry, University of North Carolina, CB 7160, Chapel Hill, NC 27599-7160, \\ USA \\ bDepartment of Biostatistics, University of North Carolina, CB 7420, Chapel Hill, NC 27599-7420, \\ USA \\ 'Department of Genetics, University of North Carolina, CB 7510, Chapel Hill, NC 27599-7264, \\ USA
}

\begin{abstract}
The relative lengths of the $2^{\text {nd }}$ and $4^{\text {th }}$ digits (2D:4D) may provide an easily measurable and stable anthropometric index of prenatal androgen exposure, but no study has examined the development of 2D:4D in infancy and the potential impact of neonatal testosterone levels. We collected 2D:4D ratios from 364 children between 0 and 2 years of age. Saliva samples were collected from 236 of these children 3 months after birth and analyzed for testosterone. In addition, 259 children provided DNA samples which were genotyped for the CAG repeat polymorphism in the androgen receptor. There was substantial variability across age in 2D:4D. Sex differences were small compared to adults and did not consistently reach statistical significance. This suggests that 2D:4D may not function well as a proxy measure of prenatal testosterone exposure in infancy. In addition, the interaction of salivary T and CAG repeats predicted right hand digit ratio at 12 months and left hand digit ratio at 12 months and 24 months in males. The interaction of salivary testosterone and CAG repeat length also predicted change in left hand 2D:4D from 2 weeks to 12 months in males. This suggests that 2D:4D in adults may reflect, in part, neonatal testosterone exposure. No significant relationships were observed within females. No significant relationships were observed when salivary testosterone and CAG repeats were examined independent of each other. Results have important implications for the design and interpretation of studies which use $2 \mathrm{D}: 4 \mathrm{D}$ as a proxy measure of prenatal testosterone exposure.
\end{abstract}

\section{Keywords}

testosterone; androgen; 2D:4D; digit ratio

\footnotetext{
(C) 2011 Elsevier Inc. All rights reserved.

Address for Correspondence: Rebecca Knickmeyer, Department of Psychiatry, 343 Medical Wings C, Campus Box \#7160, University of North Carolina, Chapel Hill NC 27599-7160. rebecca_knickmeyer@med.unc.edu, phone: 919-966-2216, fax: (919) 843-3525.

Publisher's Disclaimer: This is a PDF file of an unedited manuscript that has been accepted for publication. As a service to our customers we are providing this early version of the manuscript. The manuscript will undergo copyediting, typesetting, and review of the resulting proof before it is published in its final citable form. Please note that during the production process errors may be discovered which could affect the content, and all legal disclaimers that apply to the journal pertain.
} 


\section{Introduction}

Experiments in animals leave no doubt that androgens, especially testosterone produced in fetal and neonatal life, act on the developing organism to produce sex differences in neural structure and neuroanatomy, reproductive and social behaviors, and cognitive function later in life (De Vries \& Simerly, 2002; Simerly, 2002). Compelling evidence that early androgen exposure is also important for the sexual differentiation of the brain in humans is provided by studies of individuals with disorders of sex determination and disorders of sex differentiation, in particular, studies of girls with congenital adrenal hyperplasia (CAH) (Hines, 2002). However, it is less clear whether normal variation in early androgen exposure predicts within-sex variation in sexually dimorphic outcomes. This is largely due to inherent difficulties in measuring fetal androgen exposure.

The onset of testosterone biosynthesis occurs at about 9 weeks gestational age (Grumbach et al., 2003), and the maximal prenatal sex difference in serum levels occurs between 12 and 18 weeks gestational age. In animal models, the general critical period for sexual differentiation of the brain usually occurs when sex differences in serum testosterone are highest (Smith \& Hines, 2000). Therefore it is likely that this is an important period for masculinization of the brain in humans as well. While androgen levels can be measured in fetal blood obtained at cordocentesis or in amniotic fluid obtained at amniocentesis, these procedures incur significant fetal risk. They can only be performed in high risk pregnancies during the second and third trimesters. Serial measurements are not possible. Circulating hormone levels can be measured serially in maternal blood at any point in pregnancy, but are unlikely to accurately index fetal exposure. Hormones can also be measured in umbilical cord blood at birth, but the resulting concentrations reflect late gestation exposure, well after the hypothesized period of sexual differentiation (van de Beek et al., 2004).

Given these difficulties, there is a great deal of interest in identifying an anthropometric index of prenatal androgen exposure. It has been proposed that the relative lengths of the $2^{\text {nd }}$ and $4^{\text {th }}$ digits (2D:4D) provide just such an index (Manning et al., 1998). Since this influential paper was published over 300 publications related to 2D:4D have appeared in the literature (Voracek \& Loibl, 2009). These studies have suggested associations between 2D: 4D and a multiplicity of outcomes including: personality (Fink et al., 2004; Hampson et al., 2008; Loehlin et al., 2009), sensation seeking (Fink et al., 2006), social cognition (Williams et al., 2003), cooperative behavior (Millet \& Dewitte, 2006), spatial ability (Kempel et al., 2005; Loehlin et al., 2009), pain perception (Keogh et al., 2007), autism (de Bruin et al., 2006), schizotypal personality disorder (Walder et al., 2006), disordered eating (Klump et al., 2006; Smith et al., in press), attention deficit hyperactivity disorder (Martel et al., 2008), psychological femininity and masculinity (Scarbrough \& Johnston, 2005), sex role identity (Csatho et al., 2003), gender-typical play (Alexander, 2006; Burton et al., 2009), sexual orientation (Rahman \& Wilson, 2003), sporting ability (Manning \& Taylor, 2001), genderidentity (Wallien et al., 2008), and academic success (Romano et al., 2006).

Despite the high volume of publications, few papers utilizing 2D:4D have appeared in highimpact, broad-interest scientific journals (Voracek \& Loibl, 2009) - suggesting that the measure is not yet widely accepted. This may reflect a lack of research on the mechanisms by which 2D:4D and prenatal androgen exposure are related. It has been hypothesized that circulating prenatal androgens directly influence the development of the digits through androgen receptors, which are present in fetal cartilaginous tissue (BenHur et al., 1997). Supporting evidence comes from 3 studies of girls with CAH who showed masculinized 2D: 4D (Brown et al., 2002; Ciumas et al., 2009; Okten et al., 2002) (but note a non-replication by Buck et al. (2003)), a study of individuals with complete androgen insensitivity syndrome who showed feminized 2D:4D (Berenbaum et al., 2009), and a study showing a relationship 
between low 2D:4D and fewer CAG repeats in the transactivational domain of the androgen receptor (Manning et al., 2003), a polymorphism which is thought to impact receptor sensitivity (Callewaert et al., 2003; Irvine et al., 2000). In addition, a study of hormones measured in amniotic fluid reported that 2D:4D is significantly correlated with the ratio of testosterone to estradiol, although not with testosterone alone (Lutchmaya et al., 2004). In contrast, another study showed no relationship between 2D:4D and maternal serum androgens during the $2^{\text {nd }}$ and $3^{\text {rd }}$ trimesters or testosterone measured in umbilical cord blood (Hickey et al., 2010), but measurements of androgen in maternal serum or umbilical cord blood may not reflect fetal exposure in the critical period of interest (van de Beek et al., 2004).

If testosterone does directly alter digit growth, it is crucial to determine if that effect is limited to the prenatal period of interest. While sex differences in 2D:4D ratio are apparent by week 14 of fetal life (Galis et al., 2010; Garn et al., 1975; Malas et al., 2006), this does not rule out a role for later testosterone exposure in inter-individual variation in 2D:4D. Human males experience several organizational surges in testosterone after birth. Males are born with elevated testosterone levels as a result of the sudden drop in inhibitory estrogen produced by the placenta. Testosterone rapidly decreases in the first day of life and then begins to rise again after the first week. It peaks around the $3^{\text {rd }}$ to $4^{\text {th }}$ months of life and then drops back to very low levels by 1 year of age (Fechner, 2003; Forest et al., 1974). This is referred to as the neonatal surge. The gonads are then quiescent until puberty when levels of gonadotropins rise causing the gonads to enlarge, mature, and secrete the increased amounts of gonadal steroids typical of adulthood (Fechner, 2003). A meta-analysis suggests that 2D: 4D is not associated with adult sex hormone levels (Honekopp \& Bartholdt, 2007), and while no studies have directly tested whether testosterone levels during adolescence impact 2D:4D, a study of serial radiographs suggests that digit ratios are not strongly affected by puberty (McIntyre et al., 2005). No study has examined the development of 2D:4D in relation to the neonatal surge. McIntyre et al. (2005) did have radiographs from infants, but they averaged radiographs from the first year of life into a single score rather than examining developmental fluctuations within that time period.

The current study tests whether 2D:4D in the first 2 years of life is related to neonatal testosterone exposure at 3 months of age. Circulating testosterone levels are assessed using saliva samples. The interaction of salivary testosterone with the length of the CAG repeat in the androgen receptor is also examined as this may provide a more powerful test of testosterone effects, as it looks at the combined influence of circulating testosterone and receptor sensitivity. The study also addresses the general issue of age-related change in early life with a longitudinal sample and examines whether sex and ethnicity impact digit ratio in this time period as they do in adulthood.

\section{METHODS}

\section{Subjects}

364 children between 0 and 2 years of age are included in this study. The total sample includes 167 singletons ( 81 male, 86 female) who were enrolled as controls in a NIMH funded study, Early Brain Development in High Risk Children, and 197 twins (100 male, 97 female) who were enrolled in a NIMH funded study, Early Brain Development in Twins. Mothers were recruited during the second trimester of pregnancy from the outpatient obstetrics and gynecology clinics at UNC hospitals. Exclusion criteria at enrollment were the presence of abnormalities on fetal ultrasound or major medical or psychotic illness in the mother. Demographic data of the sample is found in Table 1. The demographic makeup of subsamples used in specific analyses is highly similar. Experiments were undertaken with the understanding and written consent of each subject's mother or father, with the approval 
of the Institutional Review Board of the University of North Carolina (UNC) School of Medicine., and in compliance with national legislation and the Code of Ethical Principles for Medical Research Involving Human Subjects of the World Medical Association (Declaration of Helsinki). The work described in this article has also been carried out in accordance with the Uniform Requirements for manuscripts submitted to Biomedical journals.

\section{D:4D Ratio}

We collected black and white photocopies of both the left and right hand of participating children at 3 study visits. Visit 1 occurred in the first month of life. Mean gestational age at visit 1 was 294.05 days. This is approximately 2 weeks post-term. We will refer to this as the 2 week visit for the rest of the paper. Visit 2 occurred at 12 months of age. Visit 3 occurred at 24 months of age. Measurements of $2^{\text {nd }}$ and $4^{\text {th }}$ digit length were taken from photocopies using Vernier calipers with an accuracy of $\pm 0.02 \mathrm{~mm}$ and repeatability of $0.01 \mathrm{~mm}$. The $2 \mathrm{D}: 4 \mathrm{D}$ ratio was calculated from digit length measured from the basal crease of the digit proximal to the palm to the tip of the digit. Each digit was measured twice with a minimum of 1 day between measurements. A single rater performed all 2D:4D measurements. The rater was blind to subject's sex. While the rater was not given explicit information as regards subject age or ethnicity, the photocopies themselves provide some limited information relevant to these parameters (e.g. size and shape of hand and skin tone). Right versus left hand could be determined from the photocopies themselves. The sequence of images was randomized with regard to sex, ethnicity, and age. Left 2D:4D was available for 210 children at Visit 1, 158 children at Visit 2, and 122 children at Visit 3. Right 2D:4D was available for 209 children at Visit 1, 153 children at Visit 2, and 123 children at Visit 3.

\section{Salivary Testosterone Levels}

Saliva samples were available for 236 children. Saliva was collected approximately 3 months post birth. Mean (SD) for gestational age at spit collection in days was 336.54 (18.69). Collection visits were scheduled for 9:00 in the morning. Mean (SD) for the actual start of collection was 9:13AM (14 minutes). $1 \mathrm{~mL}$ of passive drool was collected from each participant using a suction catheter (Centurion Healthcare Products, Howell, MO). Mean (SD) for the duration of collection was 4 minutes ( 1 minute 44 seconds). All samples were frozen within 4 hours and stored in a $-80{ }^{\circ} \mathrm{C}$ freezer.

Salivary testosterone levels were measured by enzyme immunoassay using a commercially available kit (Salimetrics, State College, PA). The intra-assay precision for samples with low testosterone levels (mean $18.12 \mathrm{pg} / \mathrm{ml}$ ) is $6.7 \%$; for high testosterone levels (mean 188.83 $\mathrm{pg} / \mathrm{ml}$ ) it is $2.5 \%$. Inter-assay precision for samples with low testosterone levels (mean 19.6 $\mathrm{pg} / \mathrm{ml}$ ) is $14.05 \%$; for high testosterone levels (mean $199.08 \mathrm{pg} / \mathrm{ml}$ ) it is $5.6 \%$. Percent recovery for this assay varies from $92 \%$ to $111.4 \%$. The minimal concentration of testosterone that can be distinguished from 0 is $<1.0 \mathrm{pg} / \mathrm{ml}$. Only 1 sample had a concentration below the detection limit. We also evaluated all samples for blood contamination using the Salimetrics Salivary Blood Contamination Enzyme Immunoassay kit which quantitatively measures transferrin, a large protein which is present in abundance in blood, but that is normally present in only trace amounts in saliva. Intra-assay precision for samples with high $(3.88 \mathrm{mg} / \mathrm{dL})$ transferrin levels is $10.2 \%$, for samples with low $(0.42$ $\mathrm{mg} / \mathrm{dL})$ transferrin levels it is $4.9 \%$. Inter-assay precision is $7.1 \%$ for low $(1.02 \mathrm{mg} / \mathrm{dL})$ and $7.2 \%$ for high $(4.93 \mathrm{mg} / \mathrm{dL})$ transferrin levels. Percent recovery varies from $91.9 \%$ to $101.5 \%$. The minimal concentration of transferrin that can be distinguished from zero is 0.08 $\mathrm{mg} / \mathrm{dL}$. 


\section{CAG repeats}

The sensitivity of the androgen receptor varies in a systematic way with the number of CAG repeats found in the first exon of the androgen receptor gene. Low numbers of CAG triplets are associated with greater receptor sensitivity (Chang, 2002). We genotyped the number of CAG repeats using buccal DNA samples. DNA was extracted using standard methods as described in the Puregene ${ }^{\circledR}$ DNA Purification Kit (Gentra Systems) using supplies from Qiagen. After extraction samples were aliquoted into 2 (23ul) tubes and stored at $-80^{\circ} \mathrm{C}$. Prior to freezing, DNA quantity and quality (indexed by the $260 / 280 \mathrm{~nm}$ ratio) were assessed by spectrophotometer (Beckman DU640, Beckman-Coulter, Brea, CA).

In order to genotype the CAG repeat polymorphism in the human androgen receptor gene, we adapted a protocol from Allen et al. (1992). First, a PCR spanning the CAG repeat polymorphism was performed. The forward primer was 1, 5'-FAM-

GCTGTGAAGGTTGCTGTTCCTCAT-3'; the reverse primer was 2, 5'TCCAGAATCTGTTCCAGAGCGTGC-3'. The PCR was carried out on a MJ Research PTC-2000 Thermocycler. The PCR product was purified using a Promega Wizard SV 96 PCR clean-up system using the standard protocol. The sizes of the PCR fragments for each sample were measured using a 3730 DNA Analyzer (Applied Biosystems, Foster City, CA) using the 600LIZ size standard for comparison. Only PCR products with a FAM labeled end are detected by the analyzer. The data was viewed using GeneMapper software (Applied Biosystems) to determine peak fragment length for each sample. Genotypes were called by visual observation of the peak fragment length within GeneMapper software. Peak fragment lengths were then converted to CAG repeat numbers. The overall no-call percentage for genotypes was $2 \% .98$ samples were run in duplicate to check for genotyping disagreements. 3 samples did not replicate (a rate of 3\%), probably due to a pipetting error. These samples were excluded from subsequent analyses. After quality control, CAG repeat length was available for 259 children.

\section{Statistical Analysis}

All statistical analyses were performed using SAS statistical software, version 9.2. For demographic variables, frequency distributions were calculated for categorical variables, and means (standard deviations) were calculated for continuous variables. Differences between genders in baseline categorical variables were assessed using Fisher's Exact test, and the Kruskal-Wallis test was used for continuous variables.

Mixed models were used for the primary analyses of this paper. Since the study sample included both singletons and twins, where data was available on both twins in a pair we included both twin members, and we treated twin pair as a random effect to capture the correlation between subjects within twin pairs. In other words, the individual twins within a pair are treated as replications, while singleton neonates had no replicates. This enables twins and singletons to be used in the same analysis without violating independence assumptions or discarding information by using only one of two twins. The unstructured covariance structure was used to capture the correlation between twins in a pair since we expected the correlation between MZ twin members would be higher than the correlation between DZ twin members (Munoz et al., 1986).

All statistical hypothesis tests were two-tailed and conducted at a significance level of 0.05 . 


\section{RESULTS}

\section{Intra-rater Reliability}

Intra-rater reliabilities for 2D:4D measures were acceptable at all ages. Intraclass correlation coefficients (Shrout-Fleiss fixed set) for the left hand were 0.86, 0.84, and 0.92 (for 2 weeks, 12 months, and 24 months respectively). Intraclass correlations for the right hand were 0.90 , 0.93 , and 0.89 (for 2 weeks, 12 months, and 24 months respectively). For all subsequent analyses 2D:4D ratios were calculated using the average of the 2 measurements. Table 2 summarizes mean 2D:4D data as well as salivary testosterone levels and CAG repeats for males and females (See Table 2).

\section{Right vs. Left Hand}

It is common practice in studies utilizing 2D:4D for researchers to measure both the left and right hand and then to perform all subsequent analyses separately for the left and right hands (thereby doubling the number of statistical tests performed). Some researchers have attempted to limit the number of statistical tests by averaging the left and right digit ratios. We tested whether it was appropriate to average the left and right hands in our age group by calculating the intraclass correlation coefficients between the hands. For the entire sample, intraclass correlation coefficients were $0.39,0.38$, and 0.44 for 2 weeks, 12 months, and 24 months, respectively. Similar results were obtained when we considered singletons alone, males alone, or females alone. This indicates that it is not appropriate to average the right and left hands, at least in this sample.

\section{Twin vs. Singleton}

Because our sample included both twins and singletons, we tested whether there was a systematic difference in 2D:4D ratios between singletons, MZ twins, and DZ twins. No significant differences were found with the exception of left hand 2D:4D at 12 months of age $(p=0.01)$. There were no consistent differences between the groups across ages or hands. Therefore, for all subsequent analyses it was assumed that twins and singletons did not differ in 2D:4D ratio.

\section{Ethnicity}

There are strong population differences in adult 2D:4D ratios, differences that explain a greater proportion of the variance in 2D:4D than sex (Manning et al., 2000). Our population is primarily Caucasian, but it also includes a significant minority of African-Americans (approximately 20\%) and a small number of Asian-Americans (approximately 3\%). Mixed models ANOVA demonstrated that African Americans had lower 2D:4D ratios than Caucasians in our sample. The magnitude of this difference was on the order of 0.01 to 0.02 and was statistically significant for the right hand at 2 weeks $(p=0.02)$. The magnitude and direction of the difference was similar, but not statistically significant, for the right hand at 12 months $(p=0.08)$ and for the left hand at 12 months $(p=0.06)$ and 24 months $(p=0.07)$. Effect sizes (Cohen's d) ranged from 0.29 to 0.45 ; these would be considered small to moderate effect sizes. Comparisons of Asian-Americans and African Americans and AsianAmericans and Caucasians were not significant, although the small number of AsianAmericans limited the power of these comparisons. Full details on effect sizes are provided in Table 3.

\section{Sexual Dimorphism}

As expected, in general males had lower 2D:4D ratios than females when correcting for ethnicity, but the difference was only statistically significant at 2 weeks of age ( $p=0.04$ and 0.01 for left and right hand respectively) (See Table 4 ). The absolute size of the difference 
was small, on the order of 0.01, but appeared fairly consistent across development. Effect sizes were also small ranging from 0.13 to 0.33 .

\section{Age Effects}

We tested the effect of age at collection on 2D:4D ratio in several, complementary ways. First, we calculated intraclass correlation coefficients to determine if measures taken at different ages are interchangeable. ICCs were 0.28 and 0.24 for the left and right hands respectively, indicating that measures taken at different ages are not interchangeable. We next examined Pearson correlations to determine if measures taken at different ages correlated with each other. We observed modest correlations: $r=0.35(p=0.0003)$ for right 2D:4D from 2 week to 12 months; $r=0.48$ ( $p<0.0001)$ for right 2D:4D from 12 months to 24 months; $r=0.38$ ( $p<0.0001$ ) for left 2D:4D from 2 week to 12 months; and $r=0.53$ ( $p$ $<0.0001$ ) for left 2D:4D from 12 months to 24 months. These analyses reaffirm our conclusion that measures taken at different ages are not interchangeable. Since ICC calculations and Pearson correlations cannot account for the non-independence of twins, we also used mixed models to compare differences between years in digit ratios, adjusting for ethnicity. There were significant differences between digit ratios collected at 1 versus 12 months of age ( $p<0.01$ for both hands) and between ratios collected at 12 versus 24 months of age ( $p=0.03$ right hand, $<0.001$ left hand). Digit ratios collected at 12 months were lower than those collected at 1 and 24 months. A similar pattern was observed in both males and females. However, examination of spaghetti plots for children with longitudinal measurements showed a high degree of individual variability in change over time (See Figure 1).

\section{Relationship of 2D:4D with Neonatal Testosterone}

Preliminary analyses indicated that salivary testosterone was significantly correlated with gestational age at collection $(r=-0.25, p<0.01)$, time of collection $(r=0.35, p<0.0001)$, and transferrin levels $(r=0.39, \mathrm{p}<0.0001)$, but not with duration of collection or duration of transport. Graphical exploration of the data suggested that the significant correlations with gestational age and time at collection were driven by 2 outliers. Correlations were no longer significant when we excluded these individuals. These individuals were excluded from all subsequent analyses using salivary testosterone. Graphical exploration also suggested that 1 individual was an outlier for transferrin $(6.68 \mathrm{mg} / \mathrm{dL})$. However, the correlation between transferrin and salivary testosterone remained significant when this individual was excluded $(\mathrm{r}=0.43, \mathrm{p}<0.0001)$. In all subsequent analyses using salivary testosterone we excluded the individual with a transferrin level of 6.68 and used transferrin as a covariate.

Because the relationship between salivary testosterone and serum testosterone may be different in males versus females (Shirtcliff et al, 2002), mixed models testing the relationship between 2D:4D and salivary T were run separately by sex. Analyses were adjusted for ethnicity and transferrin levels. The initial hypothesis was that neonatal testosterone would be inversely correlated with 2D:4D ratio - that is the same direction of effect as has been hypothesized for prenatal testosterone (Lutchmaya et al, 2004). This relationship was expected to be stronger/more consistent in males as the correlation between salivary and serum testosterone is stronger in males than females (Shirtcliff et al, 2002). There were no significant relationships between salivary testosterone and 2D:4D ratio in males or females at any age. For males the direction of effect was as hypothesized with higher 2D:4D ratios being associated with lower salivary testosterone for all comparisons except right 2D:4D at 2 week of age. In females, the direction of effect was as hypothesized for the right hand, but not for the left. We also examined whether the change in digit ratio from 2 week to 12 months in subjects with longitudinal data was predicted by salivary 
testosterone; no significant relationships were observed in either males or females (see Table $5)$.

\section{Relation of 2D:4D to CAG repeat length}

Mixed models, adjusted for ethnicity, were used to test the relationship between 2D:4D ratio and the number of CAG repeats in the androgen receptor. For the entire sample, there were no significant relationships observed. The direction and size of the effect showed no consistent pattern across hands and/or ages. This remained the case when males and females were examined separately.

\section{The interaction of CAG repeat length and salivary testosterone on 2D:4D}

We also examined whether the interaction between CAG repeat length and salivary testosterone predicted 2D:4D ratio. Because the relationship between salivary testosterone and serum testosterone may be different in males versus females, these analyses were run separately by sex. In males the interaction of salivary $\mathrm{T}$ and CAG repeats predicted right hand digit ratio at 12 months $(p=0.01)$ and left hand digit ratio at 12 months and 24 months ( $p=0.02$ for both time points). No significant relationships were observed within females (but note that the model did not converge for right 2D:4D at 24 months in females). We also examined whether the change in digit ratio from 2 weeks to 12 months in subjects with longitudinal data was predicted by the interaction of salivary testosterone and CAG repeat length. For males the interaction of salivary testosterone and CAG repeat length predicted change in left hand 2D:4D $(p=0.01)$, but not right hand 2D:4D. For females, no significant relationships were observed (see Table 5).

\section{DISCUSSION}

The primary goal of the current study was to examine the development of $2 \mathrm{D}: 4 \mathrm{D}$ in the first two years of life and determine if the neonatal surge in testosterone, experienced by males in the first year of life, influences digit ratio. We demonstrated a high level of variability and lack of stability across age in 2D:4D ratio as well as small and inconsistent sex differences which suggest that 2D:4D may not function well as a proxy measure of early testosterone exposure in infancy and early childhood. In addition, our results suggest that testosterone levels in the neonatal period may indeed modulate 2D:4D ratios in males, but this result requires replication.

First, if individual differences in 2D:4D were stable from the $2^{\text {nd }}$ trimester onwards, we would expect 2D:4D measures taken at 2 week, 12 months, and 24 months to be highly correlated. We did observe modest correlations between 2D:4D measures taken at different periods, which suggests some stability in individual differences. However, correlations were much lower than those observed in children between 6 and 8 years of age $(r=0.71)$ (McIntyre et al., 2006). ICC calculations indicated that measures taken at different ages were not interchangeable. Using mixed models to test for differences between time points showed that 2D:4D was lower at 12 months than at 2 weeks. As lower 2D:4D ratios are considered more masculine, this observation is potentially compatible with an effect of neonatal testosterone. However, if this were the case one would expect to observe this relationship in males, but not in females. In actuality, both males and females showed the same pattern. Ratios also increased from 12 months to 24 months, suggesting general age effects. In addition, examination of spaghetti plots showed a high level of individual variability in age-related change. This could be the result of measurement error or of stochastic growth processes across individuals. Bloom et al. (2010) recently reported relative immaturity of the $4^{\text {th }}$ digit relative to the $2^{\text {nd }}$ digit in children between 4 and 8 years of age. They also reported that chronological age, skeletal age, and BMI were significantly 
correlated with 2D:4D of phalange bones, but not with metacarpal bones, suggesting differential bone development 'within-digit' at this age. Although their sample was primarily male and all children were diagnosed with autism spectrum disorder, this study does suggest a non-uniform pattern of digit development which could introduce substantial within-subject variability into 2D:4D ratios. McIntyre et al. (2006) have also suggested that ratios may not be stable in children based on a study of serial radiographs in children between the ages of 6 and 8, which showed that the second digit may grow more in children relative to the fourth digit, causing $2 \mathrm{D}: 4 \mathrm{D}$ to increase with age in growing hands. $2 \mathrm{D}: 4 \mathrm{D}$ ratios in our sample are comparable to other studies in young children (Alexander et al., 2009; Lutchmaya et al., 2004), but much lower than those reported in adults (Manning et al., 1998). Considering these findings, we would strongly urge researchers collecting 2D:4D measures in children to do so within a very narrow time window. Collecting digit ratios from children of differing ages will introduce noise and result in analyses which are likely to be underpowered.

Regarding sex differences in 2D:4D in infancy, males generally had lower 2D:4D ratios than females, but this relationship was only statistically significant at 2 weeks of age. In addition, the absolute magnitude of this difference was smaller than that observed in adults (on the order of 0.01 in infants, but 0.02 in adults (Manning et al., 1998)). Effect sizes were also small (Cohen's d from 0.13 to 0.33 ). Meta-analysis indicates an effect size in older populations around 0.46, although there is substantial variation across studies (Hönekopp \& Watson, 2010). 2 small published studies have included data on 2D:4D in young children; one focused on 2 year old children (Lutchmaya et al., 2004) and one focused on infants (Alexander et al, 2009). Neither found significant sex differences. Sex differences may be observed inconsistently at this age due to growth processes. Alternatively, testosterone exposure after 2 years of age may amplify sex differences in digit ratio. A third possibility is that prenatal and neonatal testosterone may have organizational influences on bone and/or soft tissue growth of the digits that continues to unfold after the initial period of exposure.

2D:4D ratios in both infants and adults show substantial within-sex variability and a high degree of overlap between males and females. It is clear that in both groups, a substantial amount of inter-individual variability in digit ratio is unrelated to androgen exposure. One known source of variability is ethnicity. We observed that African-American infants had lower ratios than Caucasian infants; the absolute magnitude of this difference was on the order of 0.01 to 0.02; effect sizes (Cohen's d) were between 0.29 and 0.45 . The absolute differences are comparable to the differences reported in a comparison of 2 Caucasian samples (Berber and Uygar) to an Afro-Caribbean sample (children age 5-14) (Manning et al., 2004) and to differences between blacks and whites in an adult sample (primarily from the UK and USA) (Manning \& Fink, 2007). Effect sizes are similar to those in the first study, but larger than those in the latter. Ethnic differences in digit ratio could result from ethnic differences in prenatal androgenization, but this has not been empirically tested. Other factors such as nutrition and disease exposure may be involved. For example, 2D:4D ratio has been reported to be lower in individuals with the protozoan Toxoplasma gondii (Flegr et al. 2005). These potential relationships require additional research.

Finally, to more directly test the effect of neonatal testosterone exposure on digit ratio, we examined whether salivary testosterone collected around 3 months of age (the peak of the neonatal surge in males) or the interaction of salivary testosterone with the length of the CAG repeat in the androgen receptor (an index of receptor sensitivity) predicted digit ratio at 2 weeks, 12 months, and 24 months. If the neonatal surge alters digit ratios, we would expect to see a significant relationship only at 12 months and 24 months, but not at 2 weeks (unless neonatal testosterone is highly correlated with prenatal exposure - a hypothesis which has not been empirically tested). We also examined the change in digit ratio from 2 
weeks to 12 months in a subgroup of children with longitudinal data. When using salivary testosterone alone, we observed no significant relationships, although the direction of effect in males was as hypothesized. In contrast, the analyses of the interaction of salivary testosterone with CAG repeat length better fit our predictions. Within males, the interaction of salivary $\mathrm{T}$ and CAG repeats predicted right hand digit ratio at 12 months and left hand digit ratio at 12 months and 24 months, but did not predict digit ratios at 2 weeks. The interaction of salivary testosterone and CAG repeat length also predicted change in left hand 2D:4D from 2 weeks to 12 months. It appeared that this interaction was at least partially the result of a lack of the expected inverse correlation between testosterone and 2D:4D within males who had the highest number of CAG repeats (that is those with the least sensitive androgen receptor). No significant relationships were observed within females. It is not entirely surprising that we observed significant effects for the interaction of salivary $\mathrm{T}$ and CAG repeat length, but not for salivary testosterone alone or CAG repeats alone, given that circulating $\mathrm{T}$ effects on digit ratio may be moderated by receptor sensitivity and vice versa. This finding clearly requires replication, but given our results it may be more appropriate to interpret 2D:4D ratio in adulthood as an index of early testosterone exposure rather than prenatal exposure per se.

Our study does have several limitations which must be kept in mind when interpreting our results. First, we used a single salivary sample to measure circulating testosterone levels at 3 months post birth. Collection of saliva rather than serum maximized parental acceptability and minimized child distress. It is unlikely we would have achieved a reasonable sample size if we opted to use blood. However, substitution of saliva assay results for serum values is known to underestimate testosterone-behavior associations and this effect is much more pronounced for females than for males (Shirtcliff et al., 2002). In addition, collecting samples on multiple days would have allowed a more precise evaluation of individual differences in testosterone levels. Consequently, null results from this study must be treated with caution. However, where a significant correlation between $\mathrm{T}$ and digit ratio is observed this should represent a fairly conservative estimate of the correlation between $\mathrm{T}$ and digit ratio. We also observed higher levels of transferrin in saliva than expected (mean $(\mathrm{SD})=$ $0.73(0.62))$ and a moderate correlation between tranferrin and testosterone $(\mathrm{r}=0.389)$, which raises the possibility of blood contamination. For comparison, Granger et al. (2007), in a study of children between 6 and 13 years of age, reported a mean (SD) for transferrin of 0.37 (0.46) and a correlation with testosterone of 0.058 . Unfortunately, since the introduction of the transferrin assay (Schwartz \& Granger, 2004), the only published study of salivary testosterone in infants did not incorporate this measurement (Alexander et al., 2009). The makers of the transferrin assay recommend computing a regression between transferrin levels and the levels of the analyte of interest and establishing a cut score based on statistical analysis of this associative relationship (Salivary Blood Contamination EIA Kit Insert, Cat. \# 1-1302, 1-1302-5), but regression in our sample did not provide evidence of an appropriate cut point. Instead we used transferrin as a covariate in all relevant analyses.

Reassuringly, the mean (SD) for salivary testosterone in our study was highly similar to that reported by Alexander et al. (2009). It may seem surprising that we did not observe a sex difference in salivary testosterone levels given that only males have a neonatal surge in testosterone peaking at 3 months of age, however, we believe this is a consequence of differing correlations between salivary testosterone and serum testosterone in males and females. According to Salimetrics, the relationship between serum and saliva for males as determined by linear regression is y (total serum testosterone in $\mathrm{ng} / \mathrm{mL})=0.2421+$ $0.0496 * \times$ (salivary testosterone in $\mathrm{pg} / \mathrm{mL}$ ). The linear regression equation for females is $\mathrm{y}$ (total serum testosterone in $\mathrm{ng} / \mathrm{mL})=0.1415+0.0055^{*} \times$ (salivary testosterone in $\mathrm{pg} / \mathrm{mL}$ ). Assuming that the relationship between total serum testosterone and salivary testosterone in infants is similar to that seen in adults, this would indicate estimated mean serum testosterone levels of $2.20 \mathrm{ng} / \mathrm{mL}$ for males and $0.34 \mathrm{ng} / \mathrm{mL}$ for females which is consistent 
with published reports on sex differences in serum testosterone levels at 3 months (Garagorri et al., 2007; Ji et al., 2008). Finally, we have chosen to present $p$ values without adjusting for the performance of multiple tests. There is considerable debate as to when and how researchers should adjust for multiple tests (Bender \& Lange, 2001). Bonferroni adjustments are perhaps the best known method. Our results would not be significant after Bonferroni adjustment, but this method is generally considered overly conservative when the dependent variables are correlated as is the case with 2D:4D taken at different ages. In addition, many statisticians would argue that adjustments should not be made for multiple hypotheses within the context of a single study.

Despite these limitations, the current study has important implications for the design and interpretation of studies which use 2D:4D as a proxy measure of prenatal testosterone exposure. First, we demonstrated age-related changes in 2D:4D ratio in the first two years of life which could interfere with the use of 2D:4D as an index of prenatal testosterone during this period. Second, the ethnic differences which have been reported in adults in 2D:4D do appear to exist at least from birth onwards. Therefore the ethnic makeup of samples should be considered in all studies using 2D:4D. Third, sex differences in 2D:4D are not observed consistently during this period, again suggesting that 2D:4D measured in infancy and early childhood may not correlate strongly with prenatal testosterone exposure. This does not necessarily mean that 2D:4D is not a valid measure of early testosterone exposure when measured in adults and it may have some utility at earlier ages, but any results should be treated with caution until corroborating evidence using other methods, such as amniotic testosterone measurements, is available. Finally, our study provides preliminary evidence that 2D:4D ratio may be affected by neonatal testosterone levels. This result requires replication, preferably with serially collected serum samples. Ideally, such a study would also include measures of prenatal testosterone in amniotic fluid or through cordocentesis in order to test the relative contributions of prenatal and neonatal testosterone and assess 2D: $4 \mathrm{D}$ from childhood into adulthood.

\section{Highlights \\ $>\quad$ ethnicity differences in 2D:4D apparent in first 2 years of life \\ $>\quad$ sex differences in 2D:4D small and inconsistent in first 2 years of life \\ $>\quad$ interaction of neonatal testosterone and receptor sensitivity predicts 2D:4D in males \\ $>\quad$ instability in 2D:4D across age \\ $>\quad$ 2D:4D collected in early childhood may not be a reliable proxy for prenatal testosterone}

\section{Acknowledgments}

We would like to thank Dr. David A. Barrow, Director, and the staff at the UNC Bioanalytical Core Labs for carrying out the testosterone and transferrin assays for this project. We would also like to thank our participating families who have made this project possible.

\section{References}

Alexander GM. Associations among gender-linked toy preferences, spatial ability, and digit ratio: Evidence from eye-tracking analysis. Arch Sex Behav. 2006; 35(6):699-709. [PubMed: 16708283]

Alexander GM, Wilcox T, Farmer ME. Hormone-behavior associations in early infancy. Horm Behav. 2009; 56(5):498-502. [PubMed: 19699203] 
BenHur H, Thole HH, Mashiah A, Insler V, Berman V, Shezen E, Elias D, Zuckerman A, Ornoy A. Estrogen, progesterone and testosterone receptors in human fetal cartilaginous tissue: Immunohistochemical studies. Calcified Tissue Int. 1997; 60(6):520-526.

Bender R, Lange S. Adjusting for multiple testing - when and how? J Clin Epidemiol. 2001; 54(4): 343-349. [PubMed: 11297884]

Berenbaum SA, Bryk KK, Nowak N, Quigley CA, Moffat S. Fingers as a marker of prenatal androgen exposure. Endocrinology. 2009; 150(11):5119-5124. [PubMed: 19819951]

Bloom MS, Houston AS, Mills JL, Molloy CA, Hediger ML. Finger bone immaturity and 2D:4D ratio measurement error in the assessment of the hyperandrogenic hypothesis for the etiology of autism spectrum disorders. Physiol Behav. 2010; 100(3):221-224. [PubMed: 20093135]

Brown WM, Hines M, Fane B, Breedlove SM. Masculinized finger length patterns in human males and females with congenital adrenal hyperplasia. Horm Behavr. 2002; 42:380-386.

Buck JJ, Williams RM, Hughes IA, Acerini CL. In-utero androgen exposure and 2nd to 4th digit length ratio - comparisons between healthy controls and females with classical congenital adrenal hyperplasia. Hum Reprod. 2003; 18(5):976-979. [PubMed: 12721171]

Burton LA, Henninger D, Hafetz J, Cofer J. Aggression, gender-typical childhood play, and a prenatal hormonal index. Soc Behav Personal. 2009; 37(1):105-115.

Callewaert L, Christiaens V, Haelens A, Verrijdt G, Verhoeven G, Claessens F. Implications of a polyglutamine tract in the function of the human androgen receptor. Biochem Bioph Res Co. 2003; 306(1):46-52.

Chang, C. Androgens and androgen receptor: Mechanisms, functions, and clinical application. Boston: Kluwer Academic Publishers; 2002.

Ciumas C, Hirschberg AL, Savic I. High fetal testosterone and sexually dimorphic cerebral networks in females. Cereb Cortex. 2009; 19(5):1167-1174. [PubMed: 18854582]

Csatho A, Osvath A, Bicsak E, Karadi K, Manning JT, Kallai J. Sex role identity related to the ratio of second to fourth digit length in women. Biol Psychol. 2003; 62(2):147-156. [PubMed: 12581689]

de Bruin EI, Verheij F, Wiegman T, Ferdinand RF. Differences in finger length ratio between males with autism, pervasive developmental disorder-not otherwise specified, ADHD, and anxiety disorders. Dev Med Child Neurol. 2006; 48(12):962-965. [PubMed: 17109783]

de Vries, G.; Simerly, RB. Anatomy, development, and function of sexually dimorphic neural circuits in the mammalian brain. In: Pfaff, D.; Arnold, A.; Etgen, A.; Fahrbach, S.; Rubin, R., editors. Hormones, Brain and Behavior. New York: Academic Press; 2002. p. 137-191.

Fechner, PY. The biology of puberty: New developments in sex differences. In: Hayward, C., editor. Gender differences at puberty. Cambridge: Cambridge University Press; 2003. p. 17-28.

Fink B, Manning JT, Neave N. Second to fourth digit ratio and the 'big five' personality factors. Pers Indiv Differ. 2004; 37(3):495-503.

Fink B, Neave N, Laughton K, Manning JT. Second to fourth digit ratio and sensation seeking. Pers Indiv Differ. 2006; 41(7):1253-1262.

Flegr J, Hrusková M, Hodný Z, Hanusová J. Body height, body mass index, waist-hip ratio, fluctuating asymmetry and second to fourth digit ratio in subjects with latent toxoplasmosis. Parisitology. 2005; 130(6):621-628.

Forest MG, Sizonenko PC, Cathiard AM, Bertrand J. Hypophysogonadal function in humans during the first year of life: I. Evidence for testicular activity in early infancy. J Clin Invest. 1974; 53:819-828. [PubMed: 4812441]

Galis F, Ten Broek CMA, Van Dongen S, Wijnaendts LCD. Sexual dimorphism in the prenatal digit ratio (2D:4D). Arch Sex Behav. 2010; 39(1):57-62. [PubMed: 19301112]

Garagorri JM, Rodriguez G, Lario-Elboj AJ, Olivares JL, Lario-Munoz A, Orden I. Reference levels for 17-hydroxyprogesterone, 11-desoxycortisol, cortisol, testosterone, dehydroepiandrosterone sulfate and androstenedione in infants from birth to six months of age. Eur J Pediatr. 2007

Garn SM, Burdi AR, Babler WJ, Stinson S. Early prenatal attainment of adult metacarpal-phalangeal rankings and proportions. Am J Phys Anthropol. 1975; 43(3):327-332. [PubMed: 1211429]

Granger DA, Cicchetti D, Rogosch FA, Hibel LC, Teisl M, Flores E. Blood contamination in children's saliva: Prevalence, stability, and impact on the measurement of salivary cortisol, 
testosterone, and dehydroepiandrosterone. Psychoneuroendocrinology. 2007; 32(6):724-733. [PubMed: 17582690]

Grumbach, MM.; Hughes, IA.; Conte, FA. Williams Textbook of Endocrinology. In: Larsen, P.; Kronenberg, H.; Melmed, S.; Polonsky, K., editors. Williams Textbook of Endocrinology. Philadelphia: Saunders; 2003. p. 842-969.

Hampson E, Ellis CL, Tenk CM. On the relation between 2D : 4D and sex-dimorphic personality traits. Arch Sex Behav. 2008; 37(1):133-144. [PubMed: 18075733]

Hickey M, Doherty D, Hart R, Norman R, Mattes E, Atkinson H, Sloboda D. Maternal and umbilical cord androgen concentrations do not predict digit ratio (2D:4D) in girls: A prospective cohort study. Psychoneuroendocrinology. 2010; 35(8):1235-1244. [PubMed: 20299156]

Hines, M. Sexual differentiation of human brain and behavior. In: Pfaff, D.; Arnold, A.; Etgen, A.; Fahrbach, S.; Rubin, R., editors. Hormones, Brain and Behavior. New York: Academic Press; 2002. p. 425-462.

Hönekopp J, Bartholdt L. Second to fourth digit length ratio (2D:4D) and adult sex hormone levels: New data and a meta-analytic review. Psychoneuroendocrinology. 2007; 32:313-321. [PubMed: 17400395]

Hönekopp J, Watson S. Meta-analysis of digit ratio 2D:4D shows greater sex difference in the right hand. Am J Hum Bio. 2010; 22(5):619-630. [PubMed: 20737609]

Irvine RA, Ma H, Yu MC, Ross RK, Stallcup MR, Coetzee GA. Inhibition of p160-mediated coactivation with increasing androgen receptor polyglutamine length. Hum Mol Genet. 2000; 9(2): 267-274. [PubMed: 10607837]

Ji C, Huang XW, Yang RW, Wang X, Zhao ZY. Gonadotropins and sex hormones in healthy Chinese infants. Indian Pediatr. 2008; 45(6):489-492. [PubMed: 18599936]

Kempel P, Gohlke B, Klempau J, Zinsberger P, Reuter M, Hennig J. Second-to-fourth digit length, testosterone and spatial ability. Intelligence. 2005; 33(3):215-230.

Keogh E, Mounce C, Brosnan M. Can a sexually dimorphic index of prenatal hormonal exposure be used to examine cold pressor pain perception in men and women? Eur J Pain. 2007; 11(2):231236. [PubMed: 16603392]

Klump KL, Gobrogge KL, Perkins PS, Thorne D, Sisk CL, Breedlove SM. Preliminary evidence that gonadal hormones organize and activate disordered eating. Psychol Med. 2006; 36(4):539-546. [PubMed: 16336745]

Loehlin JC, Medland SE, Martin NG. Relative finger lengths, sex differences, and psychological traits. Arch Sex Behav. 2009; 38:298-305. [PubMed: 18340520]

Lutchmaya S, Baron-Cohen S, Raggatt P, Knickmeyer RC, Manning JT. 2nd to 4th digit ratios, fetal testosterone and estradiol. Early Hum Dev. 2004; 77(1-2):23-28. [PubMed: 15113628]

Malas MA, Dogan S, Evcil EH, Desdicioglu K. Fetal development of the hand, digits and digit ratio (2D : 4D). Early Hum Devt. 2006; 82(7):469-475.

Manning JT, Bundred PE, Newton DJ, Flanagan BF. The second to fourth digit ratio and variation in the androgen receptor gene. Evol Hum Behav. 2003; 24(6):399-405.

Manning JT, Fink B. Digit ratio (2D:4D), dominance, reproductive success, asymmetry, and sociosexuality in the BBC Internet Study. Am J Hum Biol. 2008; 20(4):451-461. [PubMed: 18433004]

Manning JT, Scutt D, Wilson J, Lewis-Jones DI. The ratio of 2nd to 4th digit length: A predictor of sperm numbers and levels of testosterone, LH and oestrogen. Hum Reprod. 1998; 13:3000-3004. [PubMed: 9853845]

Manning JT, Stewart A, Bundred PE, Triver RL. Sex and ethnic differences in 2nd to 4th digit ratio of children. Early Hum Dev. 2004; 80(2):161-168. [PubMed: 15500996]

Manning JT, Taylor RP. Second to fourth digit ratio and male ability in sport: implications for sexual selection in humans. Evol Hum Behav. 2001; 22(1):61-69. [PubMed: 11182575]

Martel MM, Gobrogge KL, Breedlove SM, Nigg JT. Masculinized finger-length ratios of boys, but not girls, are associated with attention-deficit/hyperactivity disorder. Behav Neurosci. 2008; 122(2): 273-281. [PubMed: 18410167]

McIntyre MH, Cohn BA, Ellison PT. Sex dimorphism in digital formulae of children. Am J Phys Anthropol. 2006; 129(1):143-150. [PubMed: 16224778] 
McIntyre MH, Ellison PT, Lieberman DE, Demerath E, Towne B. The development of sex differences in digital formula from infancy in the Fels Longitudinal Study. Proc Roy Soc B-Biol Sci. 2005; 272(1571):1473-1479.

Millet K, Dewitte S. Second to fourth digit ratio and cooperative behavior. Biol Psychol. 2006; 71(1): 111-115. [PubMed: 16024156]

Munoz A, Rosner B, Carey V. Regression-analysis in the presence of heterogeneous intraclass correlations. Biometrics. 1986; 42(3):653-658. [PubMed: 3567298]

Okten A, Kalyoncu M, Yaris N. The ratio of second- and fourth-digit lengths and congenital adrenal hyperplasia due to 21-hydroxylase deficiency. Early Hum Dev. 2002; 70:47-54. [PubMed: 12441204]

Rahman Q, Wilson GD. Sexual orientation and the 2nd to 4th finger length ratio: evidence for organising effects of sex hormones or developmental instability? Psychoneuroendocrinology. 2003; 28(3):288-303. [PubMed: 12573297]

Romano M, Leoni B, Saino N. Examination marks of male university students positively correlate with finger length ratios (2D : 4D). Biol Psychol. 2006; 71(2):175-182. [PubMed: 15978716]

Scarbrough PS, Johnston VS. Individual differences in women's facial preferences as a function of digit ratio and mental rotation ability. Evol Hum Behav. 2005; 26(6):509-526.

Schwartz EB, Granger DA. Transferrin enzyme immunoassay for quantitative monitoring of blood contamination in saliva. Clin Chem. 2004; 50(3):654-656. [PubMed: 14981036]

Shirtcliff EA, Granger DA, Likos A. Gender differences in the validity of testosterone measured in saliva by immunoassay. Horm Behav. 2002; 42(1):62-69. [PubMed: 12191648]

Simerly RB. Wired for reproduction: Organization and development of sexually dimorphic circuits in the mammalian forebrain. Ann Rev Neurosci. 2002; 25:507-536. [PubMed: 12052919]

Smith A, Hawkeswood B, Joiner T. The measure of a man: Associations between digit ratio and disordered eating in males. Int J Eat Disorders. 2010; 43(6):543-548.

Smith LL, Hines M. Language lateralization and handedness in women prenatally exposed to diethylstilbestrol (DES). Psychoneuroendocrinology. 2000; 25:497-512. [PubMed: 10818283]

van de Beek C, Thijssen JHH, Cohen-Kettenis PT, van Goozen SHM, Buitelaar JK. Relationships between sex hormones assessed in amniotic fluid, and maternal and umbilical cord serum: What is the best source of information to investigate the effects of fetal hormonal exposure? Horm Behav. 2004; 46(5):663-669. [PubMed: 15555509]

Voracek M, Loibl LM. Scientometric analysis and bibliography of digit ratio (2d:4d) research, 19982008. Psychol Report. 2009; 104(3):922-956.

Walder DJ, Andersson TLC, McMillan AL, Breedlove SM, Walker EF. Sex differences in digit ratio (2D:4D) are disrupted in adolescents with schizotypal personality disorder: Altered prenatal gonadal hormone levels as a risk factor. Schizophr Res. 2006; 86(1-3):118-122. [PubMed: 16806835]

Wallien MSC, Zucker KJ, Steensma TD, Cohen-Kettenis PT. 2D : 4D finger-length ratios in children and adults with gender identity disorder. Horm Behav. 2008; 54(3):450-454. [PubMed: 18585715]

Williams JHG, Greenhalgh KD, Manning JT. Second to fourth finger ratio and possible precursors of developmental psychopathology in preschool children. Early Hum Dev. 2003; 72:57-65.

[PubMed: 12706312]

Horm Behav. Author manuscript; available in PMC 2012 August 1. 


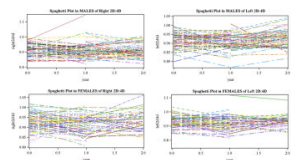

Figure 1.

Spaghetti plots demonstrating changes in 2D:4D ratio from shortly after birth to 2 years of age in children with longitudinal data.

Horm Behav. Author manuscript; available in PMC 2012 August 1. 
Table 1

Demographic Data

\begin{tabular}{|c|c|c|c|}
\hline & Male & Female & Overall \\
\hline Age at birth (Days) Mean (SD) & $264.11(14.73)$ & $264.75(15.65)$ & $264.43(15.18)$ \\
\hline Birth Weight (Grams) Mean (SD) & $2959.06(678.76)$ & $2889.83(574.78)$ & $2924.26(628.73)$ \\
\hline Maternal Age (Years) Mean (SD) & $30.11(5.62)$ & $30.20(5.42)$ & $30.16(5.51)$ \\
\hline Maternal Education (Years) Mean (SD) & $15.11(3.34)$ & $14.79(3.81)$ & $14.95(3.58)$ \\
\hline Total Household Income Mean (SD) & $74326(117192)$ & $66472(50964)$ & $70410(90409)$ \\
\hline \multicolumn{4}{|l|}{ Singleton vs Twin } \\
\hline Singleton N (\%) & $81(44.75)$ & $86(46.99)$ & $167(45.88)$ \\
\hline Twin N (\%) & $100(55.25)$ & $97(53.01)$ & $197(54.12)$ \\
\hline \multicolumn{4}{|l|}{ Within Twins : Monozygotic vs Dizygotic } \\
\hline Monozygotic N (\%) & $42(42.86)$ & $44(46.81)$ & $86(44.79)$ \\
\hline Dizygotic N (\%) & $56(57.14)$ & $50(53.19)$ & $106(55.12)$ \\
\hline \multicolumn{4}{|l|}{ Maternal Ethnicity } \\
\hline Asian N (\%) & $9(4.97)$ & $3(1.64)$ & $12(3.30)$ \\
\hline Black N $(\%)$ & $24(13.26)$ & $39(21.31)$ & $63(17.31)$ \\
\hline American Indian N (\%) & $1(0.55)$ & $0(0.00)$ & $1(0.20)$ \\
\hline White $\mathrm{N}(\%)$ & $147(81.22)$ & $141(77.05)$ & $288(79.12)$ \\
\hline
\end{tabular}


Table 2

Descriptive Statistics of 2D:4D ratios, salivary testosterone, and mean CAG repeat length by sex.

\begin{tabular}{|l|l|l|}
\hline Variable & Male & Female \\
\hline Salivary testosterone (T) pg/mL & $39.42(13.54)$ & $36.45(14.97)$ \\
\hline Mean CAG repeat number & $19.78(2.73)$ & $19.57(2.30)$ \\
\hline 2D:4D Right Year 0 & $0.92(0.04)$ & $0.93(0.05)$ \\
\hline 2D:4D Right Year 1 & $0.91(0.05)$ & $0.92(0.05)$ \\
\hline 2D:4D Right Year 2 & $0.92(0.04)$ & $0.93(0.04)$ \\
\hline 2D:4D Left Year 0 & $0.92(0.04)$ & $0.93(0.04)$ \\
\hline 2D:4D Left Year 1 & $0.91(0.04)$ & $0.91(0.05)$ \\
\hline 2D:4D Left Year 2 & $0.93(0.04)$ & $0.93(0.04)$ \\
\hline
\end{tabular}




\begin{tabular}{|c|c|c|c|c|c|c|c|}
\hline & 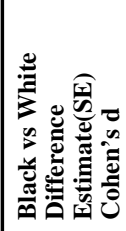 & 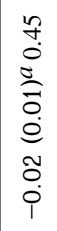 & $\begin{array}{c}0 \\
0 \\
0 \\
0 \\
0 \\
0 \\
0 \\
0 \\
\tilde{0} \\
0 \\
0 \\
0\end{array}$ & 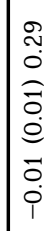 & 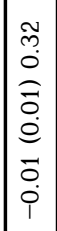 & 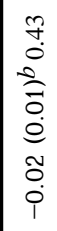 & 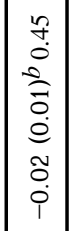 \\
\hline & 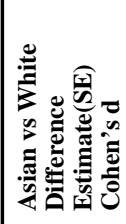 & 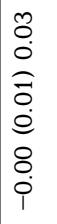 & 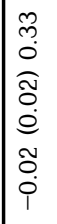 & 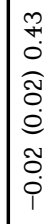 & 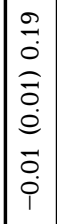 & 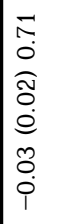 & 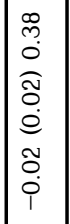 \\
\hline & 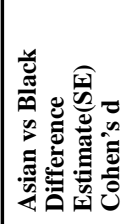 & 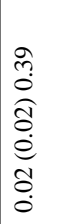 & 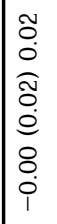 & 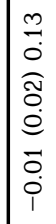 & 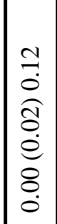 & $\begin{array}{l}\vec{m} \\
0 \\
0 \\
\hat{\tilde{O}} \\
0 \\
0 \\
\overrightarrow{0} \\
\dot{i} \\
\dot{i}\end{array}$ & $\left|\begin{array}{l}\infty \\
0 \\
0 \\
\widehat{\delta} \\
0 \\
0 \\
0 \\
0 \\
0 \\
0\end{array}\right|$ \\
\hline & 穿 & 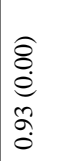 & 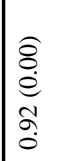 & 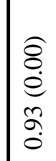 & 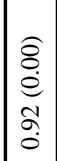 & 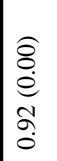 & $\left|\begin{array}{c}\hat{\sigma} \\
\stackrel{0}{0} \\
\tilde{\sigma} \\
\hat{\sigma}\end{array}\right|$ \\
\hline \multirow{3}{*}{ 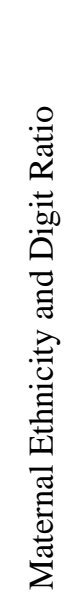 } & 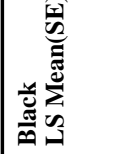 & $\begin{array}{l}\hat{\bar{a}} \\
\stackrel{e}{e} \\
\bar{a} \\
\dot{0}\end{array}$ & 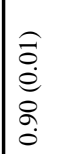 & $\begin{array}{l}\widehat{\hat{\sigma}} \\
\hat{e} \\
\bar{\sigma} \\
\hat{\sigma}\end{array}$ & $\mid \begin{array}{l}\hat{\sigma} \\
\dot{e} \\
\bar{a} \\
\dot{\partial}\end{array}$ & 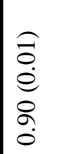 & $\left|\begin{array}{l}\hat{o} \\
\dot{e} \\
\bar{a} \\
\dot{o}\end{array}\right|$ \\
\hline & 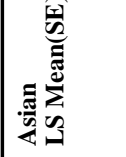 & $\begin{array}{l}\hat{\sigma} \\
\stackrel{e}{e} \\
\hat{\jmath} \\
\hat{\sigma}\end{array}$ & 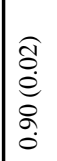 & $\begin{array}{l}\widehat{\hat{\delta}} \\
\hat{e} \\
\bar{\delta} \\
\bar{\delta}\end{array}$ & 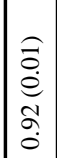 & $\begin{array}{l}\widehat{\widehat{d}} \\
\stackrel{0}{0} \\
\infty \\
\infty \\
0 \\
0\end{array}$ & 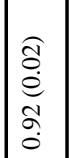 \\
\hline & 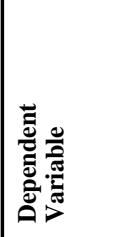 & 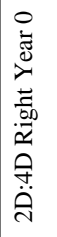 & 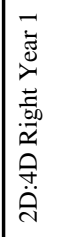 & 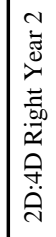 & 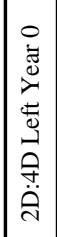 & 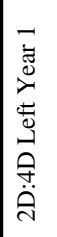 & 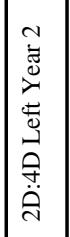 \\
\hline
\end{tabular}

Horm Behav. Author manuscript; available in PMC 2012 August 1. 
Table 4

Sex Differences in Digit Ratio

\begin{tabular}{|l|l|l|l|r|}
\hline Dependent Variable & $\begin{array}{l}\text { Male } \\
\text { LS Mean(SE) }\end{array}$ & $\begin{array}{l}\text { Female } \\
\text { LS Mean(SE) }\end{array}$ & $\begin{array}{l}\text { Gender Difference } \\
\text { Estimate(SE) }\end{array}$ & Cohen's d \\
\hline 2D:4D Right Year 0 & $0.92(0.01)$ & $0.93(0.01)$ & $-0.01(0.01)^{a}$ & 0.24 \\
\hline 2D:4D Right Year 1 & $0.91(0.01)$ & $0.91(0.01)$ & $-0.00(0.01)$ & 0.13 \\
\hline 2D:4D Right Year 2 & $0.91(0.01)$ & $0.92(0.01)$ & $-0.01(0.01)$ & 0.31 \\
\hline 2D:4D Left Year 0 & $0.91(0.01)$ & $0.93(0.01)$ & $-0.01(0.01)^{a}$ & 0.33 \\
\hline 2D:4D Left Year 1 & $0.90(0.01)$ & $0.90(0.01)$ & $-0.01(0.01)$ & 0.15 \\
\hline 2D:4D Left Year 2 & $0.92(0.01)$ & $0.93(0.01)$ & $-0.01(0.01)$ & 0.22 \\
\hline
\end{tabular}

$a_{p<0.05}$ 


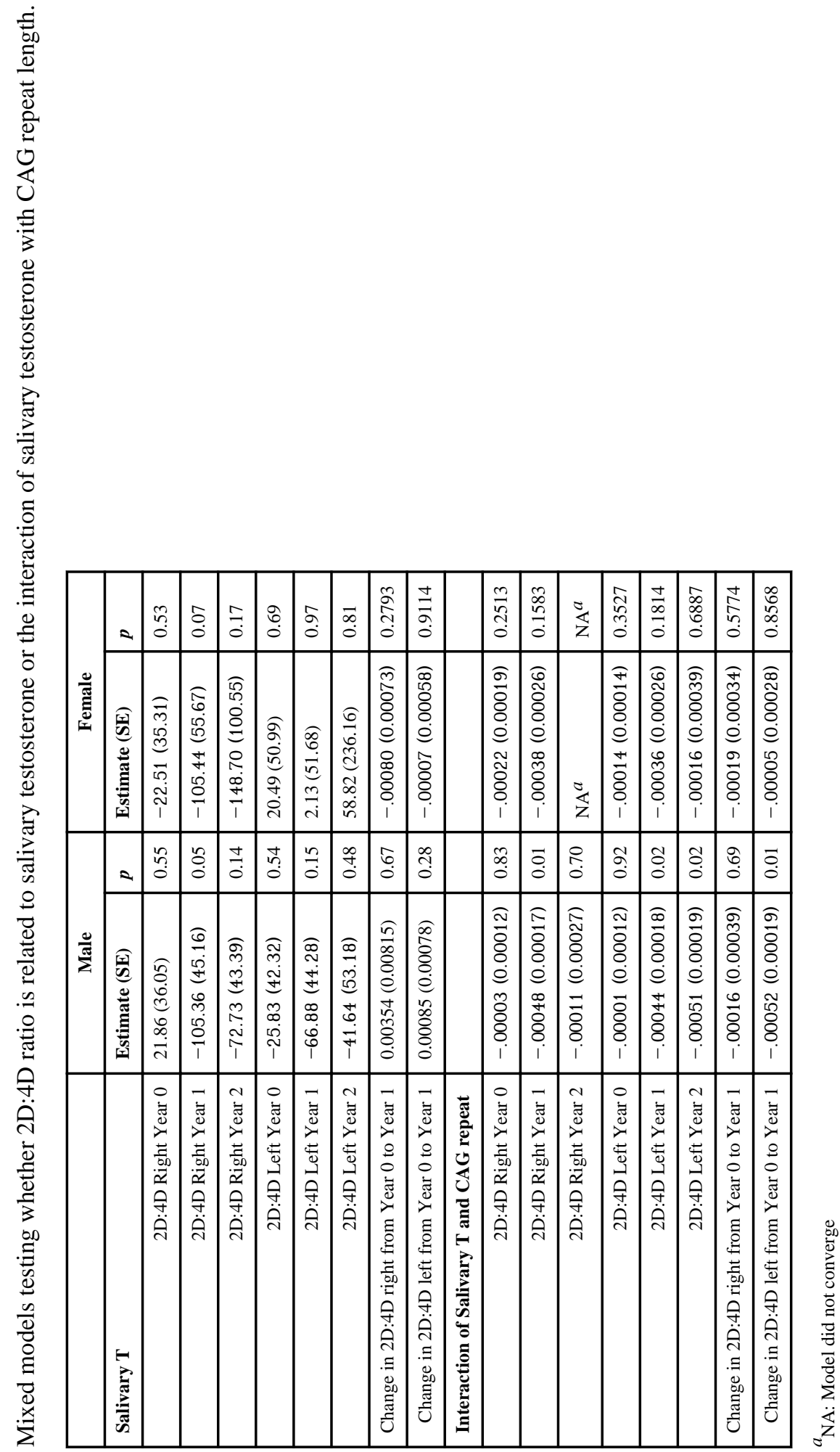

